\title{
Protease-Activated Receptor-1 and Platelet-Derived Growth Factor in Spinal Cord Neurons Are Implicated in Neuropathic Pain after Nerve Injury
}

\author{
Minoru Narita, Aiko Usui, Michiko Narita, Keiichi Niikura, Hiroyuki Nozaki, Junaidi Khotib, Yasuyuki Nagumo, \\ Yoshinori Yajima, and Tsutomu Suzuki \\ Department of Toxicology, Hoshi University School of Pharmacy and Pharmaceutical Sciences, 2-4-41 Ebara, Shinagawa-ku, Tokyo 142-8501, Japan
}

Recently, it has been reported that both thrombin-sensitive protease-activated receptor 1 (PAR-1) and platelet-derived growth factor (PDGF) are present not only in platelets, but also in the CNS, which indicates that they have various physiological functions. In this study, we evaluated whether PAR-1/PDGF in the spinal cord could contribute to the development of a neuropathic pain-like state in mice. Thermal hyperalgesia and tactile allodynia induced by sciatic nerve ligation were significantly suppressed by repeated intrathecal injection of hirudin, which is characterized as a specific and potent thrombin inhibitor. Furthermore, a single intrathecal injection of thrombin produced long-lasting hyperalgesia and allodynia, and these effects were also inhibited by hirudin in normal mice. In nerveligated mice, the increase in the binding of $\left[{ }^{35} \mathrm{~S}\right] \mathrm{GTP} \gamma \mathrm{S}$ to membranes of the spinal cord induced by thrombin and PAR-1-like immunoreactivity (IR) in the spinal cord were each greater than those in sham-operated mice. Thermal hyperalgesia and tactile allodynia induced by sciatic nerve ligation were also suppressed by repeated intrathecal injection of either the PDGF $\alpha$ receptor (PDGFR $\alpha$ )/Fc chimera protein or the PDGFR-dependent tyrosine kinase inhibitor AG17 [(3,5-di-tert-butyl-4-hydroxybenzylidene)-malononitrile]. Moreover, thermal hyperalgesia and tactile allodynia induced by thrombin in normal mice were virtually eliminated by intrathecal pretreatment with PDGFR $\alpha / F c$. In immunohistochemical studies, PAR-1-like IR-positive cells in the spinal dorsal horn were mostly colocated on PDGF-like IR-positive neuronal cells. These data provide novel evidence that PAR-1 and PDGF-A-mediated signaling pathway within spinal cord neurons may be directly implicated in neuropathic pain after nerve injury in mice.

Key words: thrombin; protease-activated receptor-1; platelet-derived growth factor; neuropathic pain; spinal cord; pain

\section{Introduction}

Recently, our understanding of the role of serine proteases such as thrombin, a key enzyme of the coagulation system, has been expanded to include actions in the nervous system (Gill et al., 1998). Thrombin affects protease-activated receptors (PARs), which are a family of G-protein-coupled receptors (Macfarlane et al., 2001). Molecular cloning has identified four PARs. Thrombin activates PAR-1, PAR-3, and PAR-4. Thrombin cleaves PARs, unmasking the "tethered ligand," an extracellular N-terminal domain that subsequently binds and activates the receptor (Steinhoff et al., 2000). It is considered that PARs are implicated in responses to injury, notably in inflammation and repair (Dai et al., 2004). In particular, PAR-1, which mediates most of the known proinflammatory actions of thrombin, is expressed by platelets, endothelial

Received Feb. 23, 2005; revised Sept. 2, 2005; accepted Sept. 9, 2005

This work was supported by a Research Grant from the Ministry of Education, Culture, Sports, Science, and Technology of Japan. We thank Masami Suzuki, Naoko Kuzumaki, Yui Kazama, and Tomoe Takagi for their expert technical assistance.

Correspondence should be addressed to either Dr. Minoru Narita or Dr. Tsutomu Suzuki, Department of Toxicology, Hoshi University School of Pharmacy and Pharmaceutical Sciences, 2-4-41 Ebara, Shinagawa-ku, Tokyo 1428501, Japan.E-mail: narita@hoshi.ac.jp and suzuki@hoshi.ac.jp.

DOI:10.1523/JNEUROSCI.2507-05.2005

Copyright $\odot 2005$ Society for Neuroscience 0270-6474/05/2510000-10\$15.00/0 cells, fibroblasts, smooth muscle cells, mast cells, neurons, and astrocytes (Suo et al., 2004). Furthermore, PAR-1 is present in the developing and mature CNS (Fang et al., 2003). Zhu et al. (2005) reported that PAR-1 is expressed not only in a subset of large-diameter primary sensory neurons but also in a subset of small- and medium-diameter primary sensory neurons of the spinal cord, which play an important role in the transmission of pain. The thrombin inhibitor hirdin, which is isolated from leech (Hirudo medicinalis), was characterized as a specific thrombin inhibitor in the late 1950s (Markwardt, 1957). In addition, the high affinity of hirudin for thrombin and the specificity of the tight and essentially irreversible binding of hirudin to thrombin has been confirmed recently (Markwardt, 2002). Therefore, hirudin is a useful tool for the elucidation of mechanisms of thrombin-induced physiological responses.

Recently, it has been reported that thrombin induces the activation of platelets and promotes the expression or the release of platelet-derived growth factor (PDGF) from $\alpha$-granule of platelets (Fager, 1995). PDGF was identified 20 years ago as a growthpromoting activity in human platelets for fibroblasts, smooth muscle cells, and glial cells. There are three PDGF isoforms (PDGF-AA, PDGF-AB, and PDGF-BB), which are homodimers or heterodimers of related A and B polypeptide chains. Two re- 
ceptors for PDGF [PDGF $\alpha$ receptor (PDGFR $\alpha$ ) and PDGFR $\beta$ ] bind the PDGF isoforms with different affinities. The PDGFR $\alpha$ binds all three PDGF isoforms with similar affinities. The binding of PDGF to PDGFR has been shown to induce homodimerization of the receptor, which facilitates the intrinsic protein tyrosine kinase (PTK) activity of PDGFR (Claesson, 1994). The activation of PTK autophosphorylates several tyrosine residues found within the cytoplasmic domain of PDGFR and provides a recognition site for intracellular signal molecules. Furthermore, it has been reported that PDGF and PDGFR could be located in myelinated and unmyelinated primary sensory neurons (Eccleston et al., 1993) and in the spinal cord (Heldin and Westermark, 1999). Thus, these findings support the idea that PDGF, which is mostly present in the blood vessels, may play a more important role in the physiological responses including pain perception than has been thought previously. In addition, as described above, thrombin could release PDGF through PAR in platelets. Together, these findings raise the possibility that PDGF associated with PAR may be implicated in pain perception. However, the contribution of a thrombin/PAR/PDGF pathway to the neuropathic pain-like state is unknown.

In the present study, therefore, we investigated the role of a spinal thrombin/PAR/PDGF-mediated signaling pathway in the development of the neuropathic pain-like state induced by partial sciatic nerve ligation in mice.

\section{Materials and Methods}

The present study was conducted in accordance with the Guiding Principles for the Care and Use of Laboratory Animals, as adopted by the Committee on Animal Research of Hoshi University, which is accredited by the Ministry of Education, Culture, Sports, Science, and Technology of Japan. Every effort was made to minimize the number and suffering of any animals used in the following experiments. Animals were used only once in the present study. All behavioral experiments were conducted in a single-blind manner to avoid the effect of subjectivity.

Animals. Male Institute of Cancer Research mice (Tokyo Laboratory Animals Science, Tokyo, Japan) weighing $\sim 25 \mathrm{~g}$ were housed at a room temperature of $23 \pm 1^{\circ} \mathrm{C}$ with a $12 \mathrm{~h}$ light/dark cycle (light on 8:00 A.M. to 8:00 P.M.). Food and water available ad libitum during the experimental period.

Neuropathic pain model. The mice were anesthetized with sodium pentobarbital $(70 \mathrm{mg} / \mathrm{kg}$, i.p.). We produced a partial sciatic nerve injury by tying a tight ligature with 7-0 or 8-0 silk suture around approximately one-third to one-half of the diameter of the sciatic nerve on the right side (ipsilateral side) under a light microscope (SD30; Olympus, Tokyo, Japan) as described previously (Malmberg et al., 1997). In sham-operated mice, the nerve was exposed without ligation.

Measurement of the latency of paw withdrawal in response to a thermal stimulus. To assess the sensitivity to thermal stimulation, each of the hindpaws of mice was tested individually using a thermal stimulus apparatus (model 33 Analgesia Meter; IITC Life Science, Woodland Hills, CA). The intensity of the thermal stimulus was adjusted to achieve an average baseline paw withdrawal latency of $\sim 8-10 \mathrm{~s}$ in naive mice. Only quick hindpaw movements (with or without licking of hindpaws) away from the stimulus were considered to be a withdrawal response. Paw movements associated with locomotion or weight shifting were not counted as a response. The paws were measured alternating between the left and right with an interval of $>3$ min between measurements. The latency of paw withdrawal after the thermal stimulus was determined as the average of three measurements per paw. Before the behavioral responses to the thermal stimulus were tested, mice were habituated for at least $1 \mathrm{~h}$ in an acrylic cylinder $(15 \mathrm{~cm}$ in height and 8 $\mathrm{cm}$ in diameter). Under these conditions, the latency of paw withdrawal in response to the thermal stimulus was tested. The latency of paw withdrawal in response to a thermal stimulus was measured before surgery and 1, 3, 5, 7, and $14 \mathrm{~d}$ after surgery.
To investigate the effect of a single intrathecal treatment with thrombin or PDGF in normal mice, the latency of paw withdrawal was measured before and after injection until the latency returned to the baseline. The latency of paw withdrawal in response to a thermal stimulus was determined as the average of both paws.

Measurement of paw withdrawal in response to a tactile stimulus. To quantify the sensitivity to a tactile stimulus, paw withdrawal in response to a tactile stimulus was measured using von Frey filaments (North Coast Medical, Morgan Hill, CA) with two different bending forces $(0.02$ and $0.16 \mathrm{~g})$. Each von Frey filament was applied to the plantar surface of the hindpaws for $3 \mathrm{~s}$, and this was repeated three times. Each of the hindpaws of the mice was tested individually. Paw withdrawal in response to a tactile stimulus was evaluated by scoring as follows: 0 , no response; 1 , a slow and/or slight response to the stimulus; 2, a quick withdrawal response away from the stimulus without flinching or licking; 3 , an intense withdrawal response away from the stimulus with brisk flinching and/or licking. Paw withdrawal in response to each filament was determined as the average of two scores per paw. Paw movements associated with locomotion or weight shifting were not counted as a response. The paws were measured alternating between left and right with an interval of $>3$ min between the measurements. Before the behavioral responses to a tactile stimulus were tested, mice were habituated for at least $1 \mathrm{~h}$ on an elevated nylon mesh floor. Under these conditions, paw withdrawal in response to a tactile stimulus was tested. The paw withdrawal threshold to the tactile stimulus was measured before surgery and the day after measurement of the thermal threshold (day 2, 4, 6, 8, and 15). To investigate the effect of a single intrathecal treatment with thrombin or PDGF in normal mice, the measurement of paw withdrawal in responses to the tactile stimulus was performed before and after the injection until the response returned to the baseline. The paw withdrawal in response to the tactile stimulus was determined as the average of both paws.

Intrathecal injection. Intrathecal injection was performed as described by Hylden and Wilcox (1980) using a $25 \mu$ l Hamilton syringe with a 30 one-half gauge needle. The needle was inserted into the intervertebral space between L5 and L6 of the spinal cord. A reflexive flick of the tail was considered to be a sign of the accuracy of each injection. The injection volume was $4 \mu \mathrm{l}$ for intrathecal injection. In the present study, intrathecal injection in mice was performed under unanesthesia.

Groups of mice were repeatedly treated intrathecally with the thrombin inhibitor hirudin (30 pmol/mouse), a recombinant mouse $\operatorname{PDGFR} \alpha / \mathrm{Fc}$ chimera protein (10 ng/mouse; PDGFR $\alpha / \mathrm{Fc}_{\mathrm{c}}$ ) or the PDGF receptor-dependent PTK inhibitor (3,5-di-tert-butyl-4hydroxybenzylidene)malononitrile (AG17) (30 nmol/mouse) 30 $\min , 1 \mathrm{~h}$, or $30 \mathrm{~min}$, respectively, before surgery and once per day for 8 consecutive days after surgery. A single intrathecal injection of thrombin ( $1 \mathrm{pmol} /$ mouse) or a recombinant human PDGF $(0.1$ $\mathrm{pmol} / \mathrm{mouse}$ PDGF) was performed in naive mice. Intrathecal pretreatment with hirudin, AG17, or PDGFR $\alpha / \mathrm{Fc}$ was performed $30 \mathrm{~min}$, $30 \mathrm{~min}$, or $1 \mathrm{~h}$, respectively, before a single intrathecal injection of thrombin or PDGF.

$\left[{ }^{35} S\right] G T P \gamma S$ binding assay. Seven days after nerve ligation or sham operation, for membrane preparation, spinal cords were rapidly excised at $4^{\circ} \mathrm{C}$. The tissue was homogenized using a Potter-Elvejham tissue grinder with a Teflon pestle in $20 \mathrm{vol}(\mathrm{w} / \mathrm{v})$ of ice-cold Tris- $\mathrm{HCl}$ buffer containing (in $\mathrm{mm}$ ): 50 Tris- $\mathrm{HCl}, \mathrm{pH} 7.4,5 \mathrm{MgCl}_{2}$, and 1 EGTA. The homogenate was centrifuged at $4^{\circ} \mathrm{C}$ for $10 \mathrm{~min}$ at $48,000 \times$ g. The pellet was resuspended in $\left[{ }^{35} \mathrm{~S}\right] \mathrm{GTP} \gamma \mathrm{S}$ binding assay buffer containing $50 \mathrm{~mm}$ Tris- $\mathrm{HCl}, \mathrm{pH} 7.4,5 \mathrm{~mm} \mathrm{MgCl}, 1 \mathrm{~mm}$ EGTA, and $100 \mathrm{~mm} \mathrm{NaCl}$ and centrifuged at $4^{\circ} \mathrm{C}$ for $10 \mathrm{~min}$ at $48,000 \times \mathrm{g}$. The final pellet was resuspended in $\left[{ }^{35} \mathrm{~S}\right] \mathrm{GTP} \gamma \mathrm{S}$ binding assay buffer and stored at $-70^{\circ} \mathrm{C}$ until use. The membrane homogenate (3-8 $\mu \mathrm{g}$ protein/assay) was incubated at $25^{\circ} \mathrm{C}$ for $2 \mathrm{~h}$ in $1 \mathrm{ml}$ of assay buffer with various concentrations of thrombin (0.001-10 $\mu \mathrm{M}$; Wako, Osaka, Japan), $30 \mu \mathrm{M}$ GDP and $50 \mathrm{pm}\left[{ }^{35} \mathrm{~S}\right] \mathrm{GTP} \gamma \mathrm{S}$ (specific activity, 1000 $\mathrm{Ci} / \mathrm{mmol}$; Amersham Biosciences, Arlington Heights, IL). The reaction was terminated by filtration using a Brandel cell harvester (Model M-24; Brandel, Gaithersburg, MD) and Whatman (Ann Arbor, MI) GF/B glass filters that had been presoaked in $5 \mathrm{mM} \mathrm{MgCl}_{2}, 50$ $\mathrm{mm}$ Tris- $\mathrm{HCl}, \mathrm{pH} 7.4$, transferred to scintillation-counting vials con- 
taining $0.5 \mathrm{ml}$ of a tissue solubilizer (Soluene-350; PerkinElmer, Boston, MA) and $4 \mathrm{ml}$ of a scintillation cocktail (Hionic Fluor; PerkinElmer), and equilibrated for $12 \mathrm{~h}$, and the radioactivity in the samples was determined with a liquid scintillation analyzer. Nonspecific binding was measured in the presence of $10 \mu \mathrm{M}$ unlabeled GTP $\gamma \mathrm{S}$. The binding of $\left[{ }^{35} \mathrm{~S}\right] \mathrm{GTP} \gamma \mathrm{S}$ was measured in the presence of GDP and the absence of agonist. The data are expressed as the mean \pm SEM for percentage stimulation. Similar results were obtained from at least three independent sets of experiments.

Sample preparation. Seven days after nerve ligation or sham operation, mice were deeply anesthetized with sodium pentobarbital (70 $\mathrm{mg} / \mathrm{kg}$, i.p.) and intracardially perfusion fixed with freshly prepared $4 \%$ paraformaldehyde in $0.1 \mathrm{M} \mathrm{PBS}, \mathrm{pH}$ 7.4. After perfusion, the lumbar spinal cord was quickly removed and postfixed in $4 \%$ paraformaldehyde for $2 \mathrm{~h}$, and then permeated with $20 \%$ sucrose in $0.1 \mathrm{M}$ PBS for $1 \mathrm{~d}$ and $30 \%$ sucrose in $0.1 \mathrm{M}$ PBS for $2 \mathrm{~d}$ with agitation. The L5 lumbar spinal cord segments were then frozen in an embedding compound (Sakura Finetechnical, Tokyo, Japan) on isopentane using liquid nitrogen and stored at $-30^{\circ} \mathrm{C}$ until use. Frozen spinal cord segments were cut with a freezing cryostat (Leica CM 1510; Leica, Wetzlar, Germany) at a thickness of $10 \mu \mathrm{m}$ and thaw mounted on poly-L-lysine-coated glass slides.

Immunohistochemistry. The spinal cord sections were blocked in $10 \%$ normal goat serum (NGS) in $0.01 \mathrm{M}$ PBS for $1 \mathrm{~h}$ at room temperature. Each primary antibody [1:50-150 thrombin R (PAR-1; Santa Cruz Biotechnology, Santa Cruz, CA), 1:3000 protein kinase C $\gamma$ (PKC $\gamma$; Santa Cruz Biotechnology), 1:120 PDGF-A (Santa Cruz Biotechnology), 1:400 neuronal nuclei (NeuN; Chemicon, Temecula, CA), 1:1000 S100 $\beta$-subunit clone SH-B1 (S100 $\beta$; Sigma, St. Louis, MO)] was diluted in $0.01 \mathrm{M}$ PBS containing $10 \%$ NGS and incubated for two nights at $4^{\circ} \mathrm{C}$. The samples were then rinsed and incubated with an appropriate secondary antibody conjugated with Alexa 488 and Alexa 546 for $2 \mathrm{~h}$ at room temperature. Because the staining intensity might vary between experiments, control sections were included in each run of staining. The slides were then coverslipped with PermaFluor aqueous mounting medium (Immunon; Thermo Electron, Pittsburgh, PA). All sections were observed with a light microscope (Olympus BX-80) and photographed with a digital camera (CoolSNAP HQ; Olympus).

$R N A$ preparation and quantitative analysis by reverse transcription$P C R$. Total RNA in the spinal cord of thrombin- or PBS-injected mice was extracted using the SV Total RNA Isolation system (Promega, Madison, WI) following the manufacturer's instructions. Purified total RNA was quantified spectrophotometrically at $A_{260}$. To prepare first-strand cDNA, $1 \mu \mathrm{g}$ of RNA was incubated in $100 \mu \mathrm{l}$ of buffer containing $10 \mathrm{~mm}$ dithiothreitol, $2.5 \mathrm{~mm} \mathrm{MgCl}_{2}$, dNTP mixture, 200 $\mathrm{U}$ of reverse transcriptase II (Invitrogen, Carlsbad, CA), and $0.1 \mathrm{~mm}$ oligo- $\mathrm{dT}_{12-18}$ (Invitrogen). The PDGF-A gene was amplified in a 50 $\mu \mathrm{l}$ PCR solution containing $0.8 \mathrm{~mm} \mathrm{MgCl}_{2}$, dNTP mixture, and DNA polymerase, with synthesized primers: a sense primer of PDGF-A, which is at position 407-423 (5'-CTGTGCCCATTCGCAGG-3') of the PDGF-A and an antisense primer at position 915-929 (5'ACCGCACGCACATTG-3'), which was designed according to GenBank sequence accession number AY324648. Samples were heated to $95^{\circ} \mathrm{C}$ for $1 \mathrm{~min}, 55^{\circ} \mathrm{C}$ for $2 \mathrm{~min}$, and $72^{\circ} \mathrm{C}$ for $3 \mathrm{~min}$. The final incubation was $72^{\circ} \mathrm{C}$ for $7 \mathrm{~min}$. The mixture was run on $2 \%$ agarose gel electrophoresis with the indicated markers and primers for the internal standard glyceraldehyde-3-phosphate dehydrogenase. The agarose gel was stained with ethidium bromide and photographed with UV transillumination. The intensity of the bands was analyzed and semiquantified by computer-assisted densitometry using NIH Image software. Values represent the mean \pm SEM of three independent experiments.

Drugs. The drugs used in the present study were thrombin (Wako); a thrombin inhibitor, hirudin (Sigma); PDGFR $\alpha /$ Fc (R \& D Systems, Minneapolis, MN); a PDGF receptor-dependent PTK inhibitor, AG17 (Calbiochem, La Jolla, CA); and PDGF (R \& D Systems). Thrombin and PDGFR $\alpha / F c$ were dissolved in sterile PBS, $\mathrm{pH}$ 7.4. Hirudin was dissolved in $0.9 \%$ sterile physiological saline. AG17 was dissolved in $0.9 \%$ sterile physiological saline containing $6 \%$ dimeth- ylsulfoxide. PDGF was dissolved in $0.1 \%$ bovine serum albumin containing $4 \mathrm{~mm} \mathrm{HCl}$.

Statistical analysis. All data are presented as the mean \pm SEM. The statistical significance of differences between groups was assessed with two-way ANOVA or one-way ANOVA followed by the Bonferroni/ Dunn multiple-comparison test or with Student's $t$ test.

\section{Results}

Thermal hyperalgesia and tactile allodynia induced by sciatic nerve ligation in mice were significantly suppressed by repeated intrathecal injection of the thrombin

\section{inhibitor hirudin}

Partial ligation of the sciatic nerve caused a marked decrease in the latency of paw withdrawal against a thermal stimulus only on the ipsilateral side in nerve-ligated mice [vs Saline-Sham group, $F_{(1,7)}=168.441, p<0.001$ (Fig. $1 A$ )]. The thermal hyperalgesia observed on the ipsilateral side in nerve-ligated mice was significantly suppressed by repeated intrathecal injection of hirudin (30 $\mathrm{pmol} / \mathrm{mouse}$ ) just before ligation and once per day for 8 consecutive days after nerve ligation [vs Saline-Ligation group, $F_{(1,9)}=$ 108.923, $p<0.001$ (Fig. 1A)].

Mice with sciatic nerve ligation also showed a marked increase in paw withdrawal in response to a tactile stimulus only on the ipsilateral side in nerve-ligated mice [vs Saline-Sham group, $F_{(1,7)}=$ 69.829, $p<0.001$ (Fig. $1 B$ ); vs Saline-Sham group, $F_{(1,7)}=124.623$, $p<0.001$ (Fig. 1C)]. Under these conditions, repeated intrathecal injection of hirudin (30 pmol/mouse) significantly suppressed the increase in paw withdrawal in response to an innocuous tactile stimulus induced by nerve ligation in mice [vs SalineLigation group, $F_{(1,9)}=40.565, p<0.001$ (Fig. $1 B$ ); vs SalineLigation group, $F_{(1,9)}=37.352, p<0.001$ (Fig. $1 C$ ) ]. In addition, the recovery of the persistent reduction in the thermal threshold by hirudin lasted even after treatment with hirudin was terminated (from day 9 to day 15) [vs Saline-Ligation group, $F_{(1,9)}=$ 34.934, $p<0.001$ (Fig. $1 B$ ); vs Saline-Ligation group, $F_{(1,9)}=$ 51.586, $p<0.001$ (Fig. 1C)].

Repeated intrathecal injection of hirudin at the doses used in the present study failed to affect thermal and tactile thresholds on the contralateral side in nerve-ligated mice and on both sides in sham-operated mice (data not shown).

\section{$\left[{ }^{35} \mathrm{~S}\right] \mathrm{GTP} \gamma \mathrm{S}$ binding by the PAR agonist thrombin to membranes of the spinal cord was significantly increased in nerve-ligated mice}

The ability of the endogenous PAR ligand thrombin to activate G-proteins in the spinal cord of sham-operated or nerveligated mice was examined by monitoring the binding of $\left[{ }^{35} \mathrm{~S}\right] \mathrm{GTP} \gamma \mathrm{S}$ to spinal cord membranes. Thrombin $(0.001-10$ $\mu \mathrm{M})$ produced a concentration-dependent increase in the binding of $\left[{ }^{35} \mathrm{~S}\right] \mathrm{GTP} \gamma \mathrm{S}$ to the L5 lumbar spinal cord membranes obtained from sham-operated mice. In membranes of the spinal cord from nerve-ligated mice, the increase in $\left[{ }^{35} \mathrm{~S}\right] \mathrm{GTP} \gamma \mathrm{S}$ binding induced by thrombin was significantly greater than that obtained from sham-operated mice $\left(F_{(1,90)}=\right.$ 141.7; $p<0.001$ ) (Fig. 2).

PAR-1-like immunoreactivity in the dorsal horn of the mouse spinal cord was increased by sciatic nerve ligation

PAR-1-like immunoreactivity (IR) was detected on the ipsilateral side of the L5 lumbar spinal dorsal horn of sham-operated mice (Fig. 3A). Seven days after sciatic nerve ligation, PAR-1- 


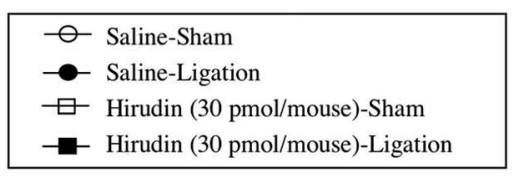

(A)

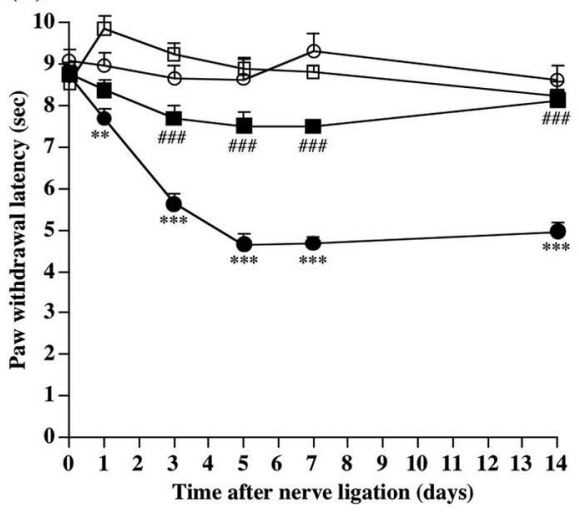

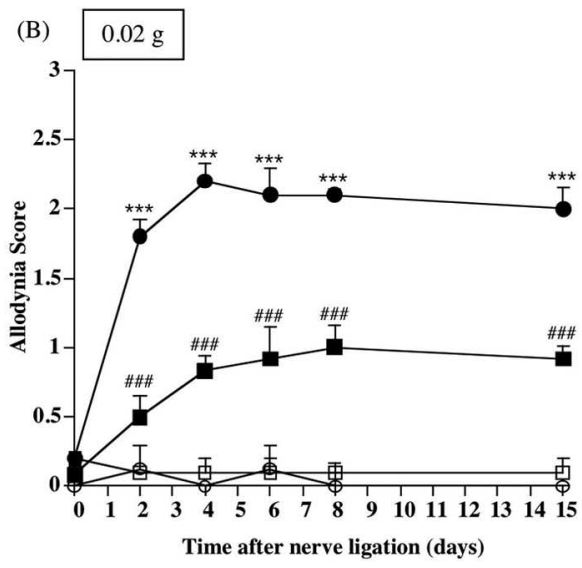

(C) $0.16 \mathrm{~g}$

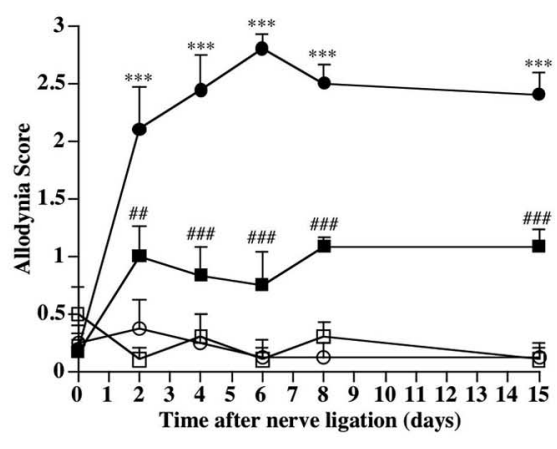

Figure 1. $\quad \boldsymbol{A}-\boldsymbol{C}$, Effect of repeated intrathecal injection of a thrombin inhibitor, hirudin, on thermal hyperalgesia $(\boldsymbol{A})$ and tactile allodynia $(\boldsymbol{B}, \boldsymbol{C})$ in sham-operated or nerve-ligated mice. Tactile stimulus was applied using filaments with two different bending forces $[0.02 \mathrm{~g}(\boldsymbol{B})$ and $0.16 \mathrm{~g}(\boldsymbol{C})$. sec, Seconds. Groups of mice were repeatedly treated intrathecally with hirudin (30 pmol/mouse) or saline $30 \mathrm{~min}$ before surgery (day 0 ) and once per day for 8 consecutive days after surgery. From day 9 to day 15 after surgery, mice were not treated with hirudin. Each point represents the mean \pm SEM of five to seven mice. ${ }^{* *} p<0.01$ and ${ }^{* * *} p<0.001$ versus Saline-Sham group; ${ }^{\# \#} p<0.01$ and ${ }^{\# \# \#} p<0.001$ versus Saline-Ligation group. Error bars represent SEM.
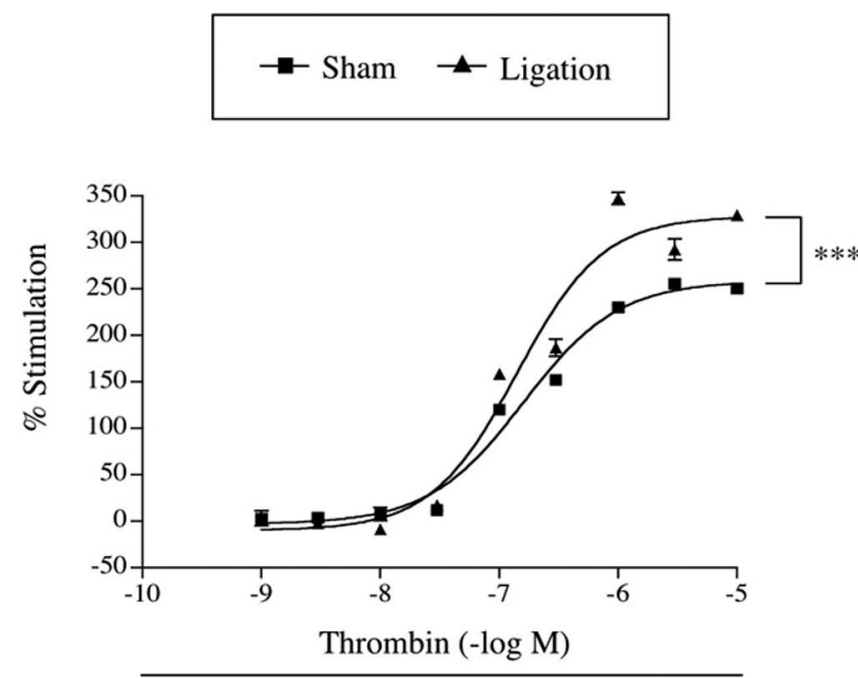

7 days after nerve ligation

Figure 2. Comparison of the stimulation of $\left[{ }^{35} \mathrm{~S}\right] \mathrm{GTP} \gamma \mathrm{S}$ binding by the PAR agonist thrombin to membranes of the spinal cord obtained from sham-operated or nerve-ligated mice. Sample preparation was performed at $7 \mathrm{~d}$ after nerve ligation. The spinal cord membranes were incubated with [ $\left.{ }^{35} \mathrm{~S}\right] \mathrm{GTP} \gamma \mathrm{S}(50 \mathrm{pm})$ and GDP $(30 \mu \mathrm{m})$ with or without thrombin. The data are shown as the percentage of basal $\left[{ }^{35} \mathrm{~S}\right] \mathrm{GTP} \gamma \mathrm{S}$ binding measured in the presence of GDP and the absence of thrombin. Values represent the mean \pm SEM of three samples. $F_{(1,90)}=141.7$ and $p<0.001$ versus Sham group. Error bars represent SEM.

like IR in lamina II and III of the ipsilateral side of the L5 lumbar spinal dorsal horn was increased compared with that observed in sham-operated mice (Fig. 3B). Furthermore, the increased PAR-1-like IR in the spinal cord after nerve injury was colocalized with PKC $\gamma$, which is highly limited to neuronal cells in the inner part of lamina II of the dorsal horn of the spinal cord (Fig. 4).
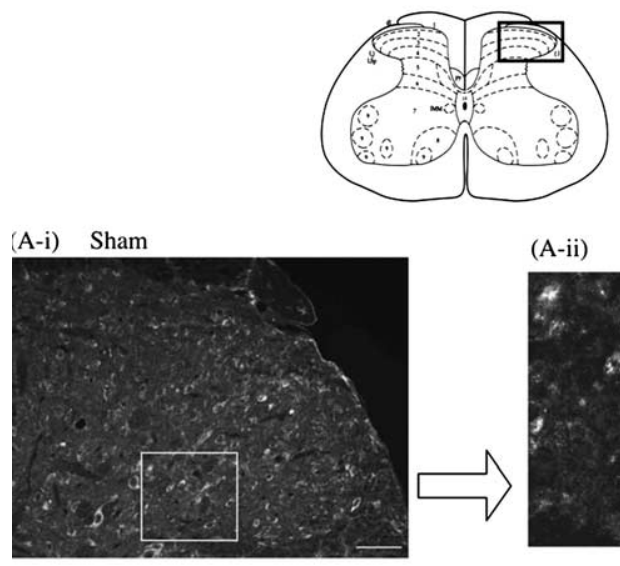

(A-ii) Enlarged

(B-i) Ligation
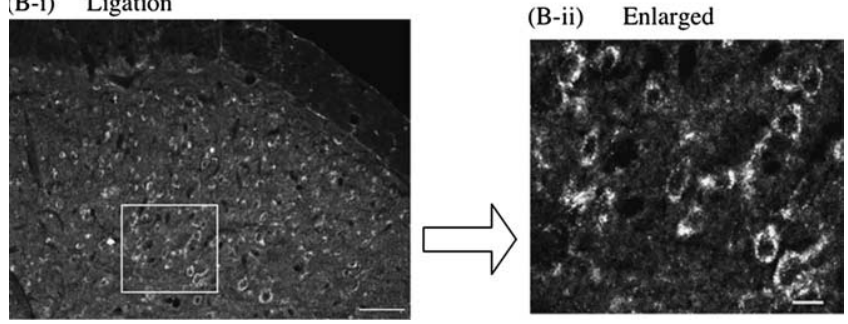

Figure 3. Increase in PAR-1-like IR on the ipsilateral superficial dorsal horn of the $L 5$ lumbar spinal cord in nerve-ligated mice $(\boldsymbol{B}-\boldsymbol{i}, \boldsymbol{B}$-ii) compared with that in sham-operated mice ( $\boldsymbol{A}$-i, $A$-ii). Spinal cord slices were prepared $7 \mathrm{~d}$ after sham operation or nerve ligation in mice. Scale bars: $\boldsymbol{A}-\boldsymbol{i}, \boldsymbol{B}-\boldsymbol{i}, 50 \mu \mathrm{m} ; \boldsymbol{A}-i \boldsymbol{i}, \boldsymbol{B}-\boldsymbol{i i}, 10 \mu \mathrm{m}$.

Thermal hyperalgesia and tactile allodynia induced by a single intrathecal treatment with thrombin in normal mice were suppressed by intrathecal pretreatment with hirudin We next investigated whether exogenous intrathecal treatment with thrombin could cause a hyperalgesic or allodynic response in normal mice. A single intrathecal injection of 
(A)

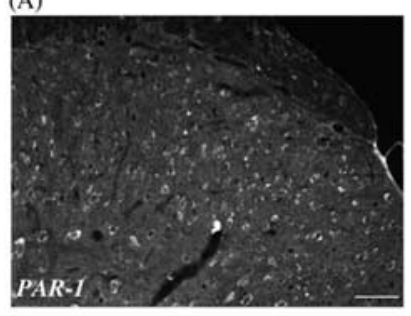

(C-i)
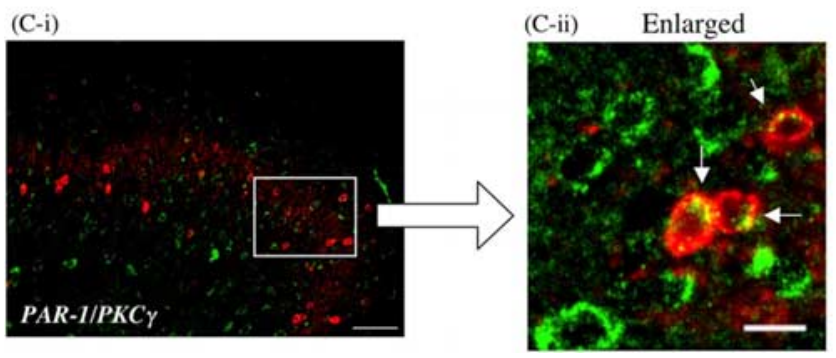

Figure 4. $A, B$, Colocalization of PAR- $1(A)$ with PKC $\gamma$, which is highly limited to the inner part of lamina Il in the dorsal horn of the mouse spinal cord $(\boldsymbol{B}) .(-\boldsymbol{i}, \mathbf{C}-\boldsymbol{i i}$, The green labeling for PAR-1 and the red labeling for PKC $\gamma$ show colocalization in the dorsal horn of the spinal cord. PAR-1-like IR is seen in the membrane of PKC $\gamma$-labeled cells in the dorsal horn of the spinal cord (arrowhead in C-ii). Scale bars: $A, B, C-i, 50 \mu \mathrm{m} ; C-i i, 10 \mu \mathrm{m}$.

thrombin ( $1 \mathrm{pmol} / \mathrm{mouse}$ ) produced marked thermal hyperalgesia and tactile allodynia in normal mice after injection, and these effects lasted for 9-10 d after injection [vs SalinePBS group, $F_{(1,10)}=605.881, p<0.001$ (Fig. 5A); vs Saline-PBS group, $F_{(1,10)}=138.103, p<0.001$ (Fig. $5 B$ ); vs Saline-PBS group, $F_{(1,10)}=247.557, p<0.001$ (Fig. $5 C$ )]. The long-lasting thermal hyperalgesia and tactile allodynia caused by an exogenous single intrathecal injection of thrombin were abolished by intrathecal pretreatment with the thrombin inhibitor hirudin (30 pmol/mouse) [vs Saline-Thrombin group, $F_{(1,10)}=818.014, p<0.001$ (Fig. 5A); vs Saline-Thrombin group, $F_{(1,10)}=81.366, p<0.001$ (Fig. 5B); vs SalineThrombin group, $F_{(1,10)}=111.593, p<0.001$ (Fig. 5C)].

PDGF-A-like immunoreactivity was detected in the neuron and astrocytes in the mouse spinal cord

We investigated the localization of PDGF-A in the L5 lumbar spinal cord in mice using immunohistochemical analysis. PDGF-A-like IR was detected in the superficial laminas and inner part of the L5 lumbar spinal cord. Furthermore, PDGFA-like IR was principally colocalized with the neuron-specific nuclear protein marker NeuN-positive cells in the superficial and inner part of the dorsal horn. Astrocytes in the dorsal horn of the spinal cord were stained with $S 100 \beta$, a specific marker for astrocytes. PDGF-A-like IR was observed occasionally in $S 100 \beta$-positive cells in the dorsal horn of the spinal cord (Fig. 6).

Thermal hyperalgesia and tactile allodynia induced by sciatic nerve ligation in mice were suppressed by repeated intrathecal injection of PDGFR $\alpha / F c$ Repeated intrathecal injection of $\operatorname{PDGFR} \alpha / \mathrm{Fc}$ (10 ng/mouse) just before and once per day for 8 consecutive days after nerve ligation reversed the decreased thermal and tactile threshold on the ipsilateral side of nerve-ligated mice [vs PBS-Ligation group, $F_{(1,10)}=179.88, p<0.001$ (Fig. $7 A$ ); vs PBS-Ligation group, $F_{(1,10)}=68.049, p<0.001$ (Fig. $7 B$ ); vs PBSLigation group, $F_{(1,10)}=47.454, p<0.001$ (Fig. 7C)]. The same treatment had no effect on the latency of paw withdrawal after a thermal or tactile stimulus on the contralateral side in nerve-ligated mice and on both sides in sham-operated mice (data not shown).

Thermal hyperalgesia and tactile allodynia induced by sciatic nerve ligation were significantly reversed by repeated intrathecal injection of the PDGF receptor-dependent PTK inhibitor AG17

To investigate whether the activation of PTK mediated by PDGF receptor could be directly involved in the neuropathic

$$
\begin{aligned}
& - \text { - Saline-PBS } \\
& - \text { Saline-Thrombin (1 pmol/mouse) } \\
& \square \text { Hirudin (30 pmol/mouse)-PBS } \\
& - \text { Hirudin ( } 30 \mathrm{pmol} / \text { mouse)-Thrombin (1 pmol/mouse) }
\end{aligned}
$$

(A)

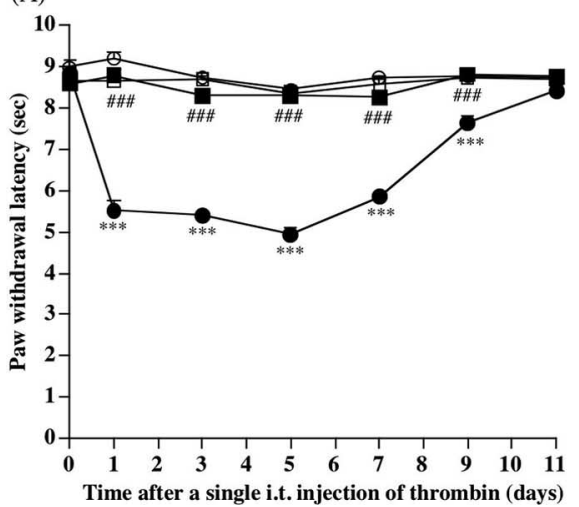

(B)
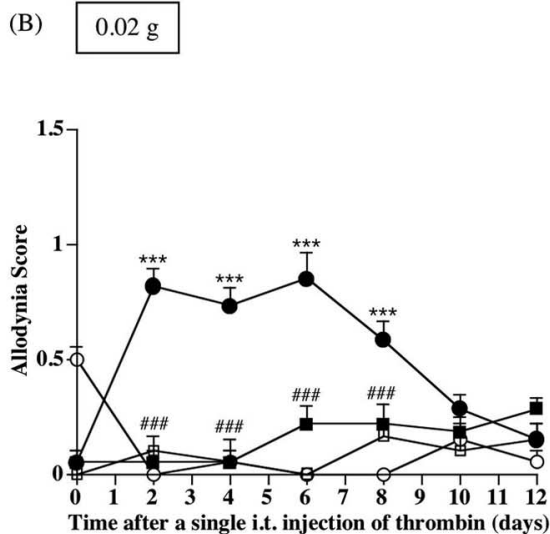

(C) $0.16 \mathrm{~g}$

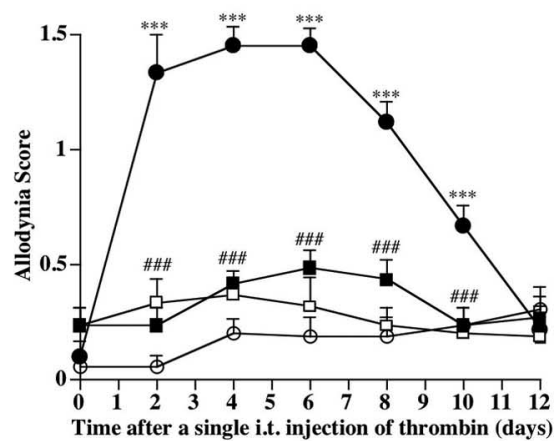

Figure 5. $\quad \boldsymbol{A}-\boldsymbol{C}$, Effect of a single intrathecal injection of thrombin on paw withdrawal responses to the thermal $(\boldsymbol{A})$ and tactile $(\boldsymbol{B}, \boldsymbol{C})$ stimulus in normal mine. sec, Seconds. $\boldsymbol{B}, \boldsymbol{C}$, Tactile stimulus was performed using filament with two different bending forces $[0.02 \mathrm{~g}(\boldsymbol{B})$ and $0.16 \mathrm{~g}(\boldsymbol{C})]$. Groups of mice were repeatedly treated intrathecally with a thrombin inhibitor hirudin $(30 \mathrm{pmol} / \mathrm{mouse})$ or saline $30 \mathrm{~min}$ before a single intrathecal injection of thrombin and once per day for 12 consecutive days after injection. Each point represents the mean \pm SEM of six mice. ${ }^{* * *} p<0.001$ versus Saline-PBS group; ${ }^{\# \#} p<0.01$ and ${ }^{\# \# \#} p<0.001$ versus Saline-Thrombin group. i.t., Intrathecal. Error bars represent SEM. 
(A)

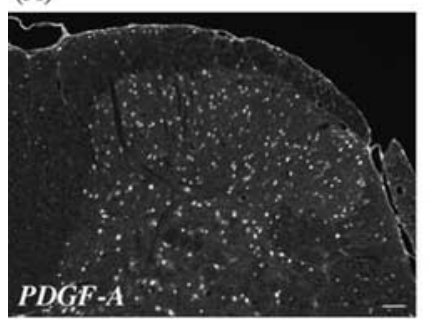

(C-i)

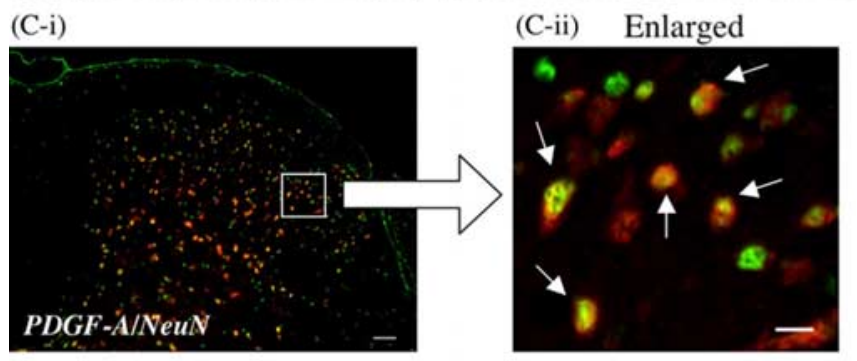

(D)

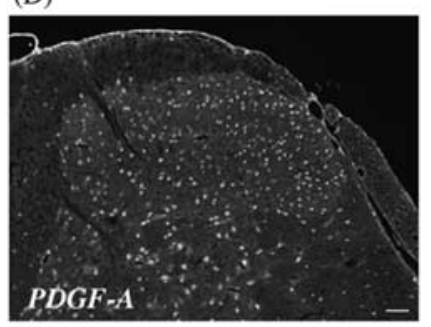

(E)

(F-i)

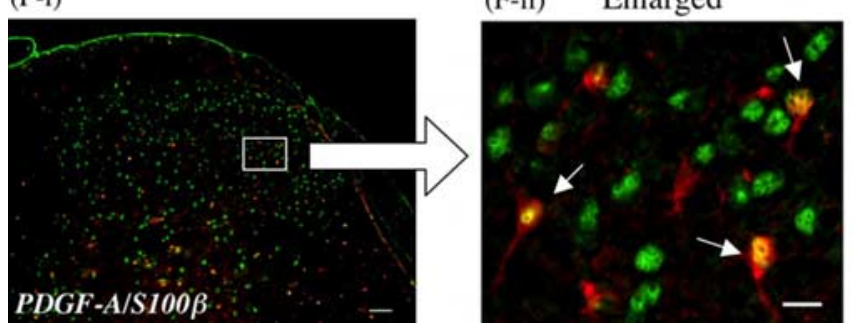

Figure 6. Colocalization of PDGF-A $(\boldsymbol{A}, \boldsymbol{D})$ with $\operatorname{NeuN}(\boldsymbol{B})$, a neuron-specific nuclear protein marker, or $\$ 100 \beta(\boldsymbol{E})$, a specific marker for astrocytes, in the dorsal horn of the mouse spinal cord. The green labeling for PDGF-A and the red labeling for NeuN or $\$ 100 \beta$ show colocalization in the dorsal horn of the spinal cord (C-i, $\mathbf{C}-\boldsymbol{i i}$, or $\boldsymbol{F}$-i, $\boldsymbol{F}$-ii). PDGF-A-like IR is exclusively observed on NeuN-labeled cells (C-ii) and partially observed on $\$ 100 \beta$-labeled cells in the dorsal horn of the spinal cord (F-ii). Scale bars: $\boldsymbol{A}, \boldsymbol{B}, \boldsymbol{C}-\boldsymbol{i}, \boldsymbol{D}, \boldsymbol{E}, \boldsymbol{F}-\boldsymbol{i}, 50 \mu \mathrm{m} ; \boldsymbol{C}-\boldsymbol{i i}, \boldsymbol{F}-\boldsymbol{i i}, 10 \mu \mathrm{m}$.

pain-like state induced by nerve ligation, groups of mice were treated intrathecally with the PDGF receptor-dependent PTK inhibitor AG17 (30 nmol/mouse) just before surgery and once per day for 8 consecutive days after nerve ligation. The thermal hyperalgesia and tactile allodynia induced by nerve ligation were significantly reversed by chronic intrathecal treatment with AG17 [vs Vehicle-Ligation group, $F_{(1,11)}=116.508, p<0.001$ (Fig. $8 A$ ); vs Vehicle-Ligation group, $F_{(1,11)}=20.928, p<0.001$ (Fig. $8 B$ ); vs VehicleLigation group, $F_{(1,11)}=25.063, p<0.001$ (Fig. 8C)]. Such treatment had no effect on the latency of paw withdrawal on the contralateral side in nerve-ligated mice or on both sides in shamoperated mice (data not shown).

Thermal hyperalgesia and tactile allodynia induced by a single intrathecal treatment with PDGF in normal mice were suppressed by intrathecal pretreatment with AG17

To investigate whether PDGF could cause a hyperalgesic or allodynic response in normal mice, groups of normal mice were treated intrathecally with PDGF. A single intrathecal injection of PDGF (0.1 pmol/mouse) produced marked thermal hyperalgesia and tactile allodynia in normal mice after injection, and this effect lasted for 8-9 d after injection [vs Vehicle-PBS group, $F_{(1,8)}=$ 164.250, $p<0.001$ (Fig. 9A); vs Vehicle-PBS group, $F_{(1,8)}=$ 197.951, $p<0.001$ (Fig. 9B); vs Vehicle-PBS group, $F_{(1,8)}=93.523, p<0.001$ (Fig. 9C)]. The long-lasting thermal hyperalgesia and tactile allodynia caused by an exogenous single intrathecal injection of PDGF were abolished by intrathecal pretreatment with the PDGF receptor-dependent PTK inhibitor AG17 (30 nmol/mouse) [vs Vehicle-PDGF group, $F_{(1,8)}=376.449, p<0.001$ (Fig. 9A); vs Vehicle-PDGF group, $F_{(1,8)}=49.965, p<0.001$ (Fig. 9B); vs Vehicle-PDGF group, $F_{(1,8)}=$ 68.029, $p<0.001$ (Fig. 9C)].

Thermal hyperalgesia and tactile allodynia induced by a single intrathecal treatment with thrombin in normal mice were significantly eliminated by repeated intrathecal pretreatment with PDGFR $\alpha / F c$

Facilitation of the activation of a thrombin/PAR-1/PDGF pathway in the spinal cord may play an important role in the development of the neuropathic pain-like state in mice. The subsequent study was undertaken to investigate whether spinal PDGF could be involved in the thermal hyperalgesia or tactile allodynia observed with a single intrathecal injection of thrombin. The thermal hyperalgesia and tactile allodynia induced by a single intrathecal injection of thrombin were significantly eliminated by repeated intrathecal pretreatment with PDGFR $\alpha / F c$ just before injection and once per day for 12 consecutive days after injection [vs PBS-Thrombin group, $F_{(1,9)}=463.624, p<0.001$ (Fig. $10 A$ ); vs PBS-Thrombin group, $F_{(1,9)}=38.222, p<0.001$ (Fig. $10 B$ ); vs PBS-Thrombin group, $F_{(1,9)}=70.964, p<0.001$ (Fig. 10C)]. Under these conditions, there were no differences between PBS- and thrombin-injected mice with regard to mRNA levels of PDGF-A in the spinal cord (Fig. 11).

PAR-1-positive cells were clearly colocalized with PDGF-Alike immunoreactivity in the dorsal horn of the spinal cord of nerve-ligated mice

The key approach in the present study was to investigate the colocalization of PAR-1 with PDGF-A in the dorsal horn of the spinal cord of nerve-ligated mouse. Interestingly, almost all of the PAR-1-positive cells in the dorsal horn of the spinal cord of nerve-ligated mice were clearly colocalized with PDGF-A-like IR, indicating that PDGF-A-like IR is highly located on PAR-1-positive neuronal cells (Fig. 12).

\section{Discussion}

A very large number of studies have confirmed that a serine protease, thrombin, is a major stimulus for platelets, and initiates a series of coordinated events that result in platelet aggregation in vitro or in vivo (Macfarlane et al., 2001). In addition to its well known role in the platelet aggregation cascade, thrombin has been implicated in degenerative as well as protective mechanisms in the CNS. It is of interest to note that PAR-1, one of the thrombin receptor subtypes, is expressed in a subset of small and medium diameter of primary sensory neurons, suggesting that a thrombin/PAR-1 pathway plays a possible role in the transmission of pain (Zhu et al., 2005). It has been reported that responses to thrombin were found to be blocked by the specific thrombin inhibitor hirudin, a hirudin-derived peptide, which reflects the thrombin-specific nature of the cloned receptor. Several studies 
have demonstrated that the response to thrombin is unrelated to the proteolytic properties of the enzyme, but rather the hirudin-like binding domain appears to be the important feature of the protein. Mutation of the $\mathrm{N}$ terminus identified the presence of a hirudin-like domain that was essential for high-affinity binding and the potent effects of thrombin (Macfarlane et al., 2001). The hirudin-like thrombin binding sequence has been identified in PAR-1. This would perhaps allow highaffinity binding to PAR-1 in the hirudinlike binding domain. In the present study, we first investigated the role of a spinal thrombin/PAR-1 pathway in the development of a neuropathic pain-like state in mice. Thermal hyperalgesia and tactile allodynia induced by sciatic nerve ligation were significantly suppressed by intrathecal pretreatment with hirudin just before and once per day for the first $7 \mathrm{~d}$ after surgery. Interestingly, the recovery of the persistent reduction in the thermal threshold by hirudin lasted even after treatment with hirudin was discontinued, which indicates the importance of the initial blockade of PAR-1 for inhibiting the development of a neuropathic pain-like state. In our preliminary study, we also investigated whether the thrombin/PAR-1 pathway within the spinal cord could be involved in the maintenance, as well as the development, of a neuropathic pain-like state in mice. The developed neuropathic pain-like state was significantly suppressed even by repeated intrathecal posttreatment with hirudin, which was started from $7 \mathrm{~d}$ after sciatic nerve ligation (thermal hyperalgesia, $66.4 \pm 2.68 \%$ of maximum inhibition; tactile allodynia, $82.5 \pm 7.85 \%$ of maximum inhibition). These results suggest that the thrombin/PAR-1 pathway within the spinal cord may also contribute to the maintenance of a neuropathic pain-like state. Furthermore, we demonstrated here that an exogenous single intrathecal injection of thrombin produced long-lasting thermal hyperalgesia and tactile allodynia in normal mice. These responses were abolished by intrathecal pretreatment with hirudin. These findings indicate that the spinal thrombin/PAR-1 pathway may be directly involved in the development of a neuropathic pain-like state caused by nerve ligation in mice.

Additional evidence for the contribution of a spinal thrombin/PAR-1 pathway to a neuropathic pain-like state was obtained by an $\left[{ }^{35} \mathrm{~S}\right] \mathrm{GTP} \gamma \mathrm{S}$ binding assay and immunohistochemical approach. Possible changes in PAR-1 func-

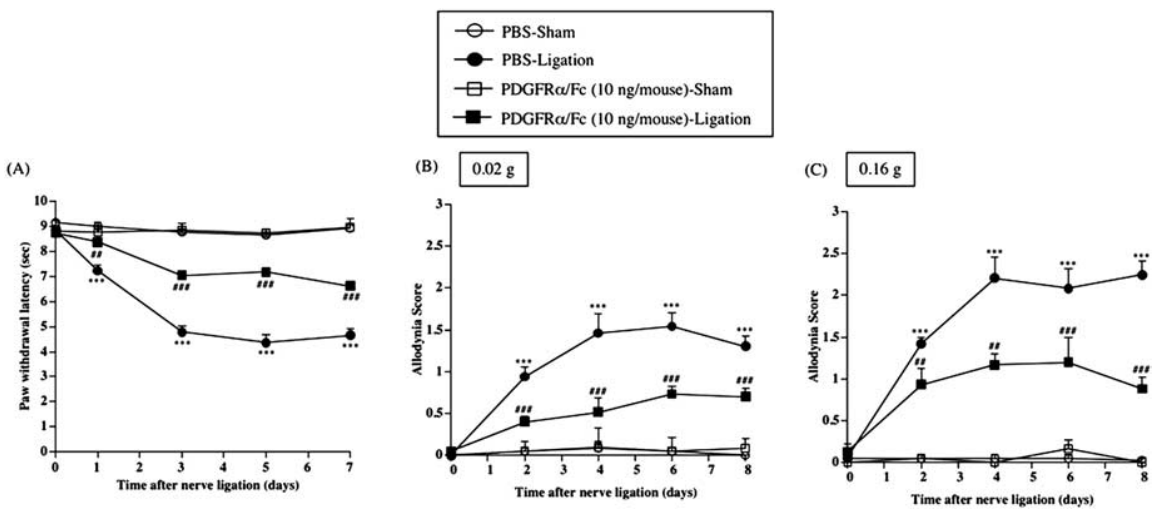

Figure 7. $\quad \boldsymbol{A}-\boldsymbol{C}$, Effect of repeated intrathecal injection of PDGFR $\alpha / F c$ on thermal hyperalgesia $(\boldsymbol{A})$ and tactile allodynia $(\boldsymbol{B}, \boldsymbol{C})$ in sham-operated or nerve-ligated mice. sec, Seconds. $\boldsymbol{B}, \boldsymbol{C}$, Tactile stimulus was applied using filaments with two different bending forces $[0.02 \mathrm{~g}(\boldsymbol{B})$ and $0.16 \mathrm{~g}(\boldsymbol{C})]$. Groups of mice were repeatedly treated intrathecally with PDGFR $\alpha / \mathrm{Fc}$ (10 $\mathrm{ng} / \mathrm{mouse}$ ) or sterile PBS $1 \mathrm{~h}$ before surgery (day 0 ) and once per day for 8 consecutive days after surgery. Each point represents the mean \pm SEM of five to six mice. ${ }^{* * *} p<0.001$ versus PBS-Sham group; ${ }^{\# \#} p<0.01$ and ${ }^{\# \# \#} p<0.001$ versus PBS-Ligation group. Error bars represent SEM.
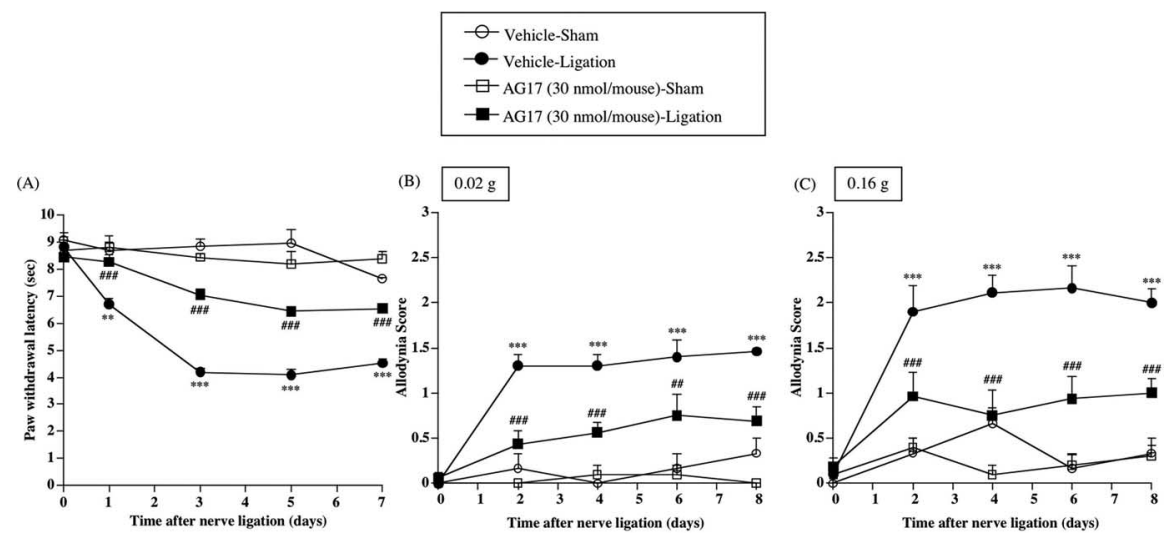

Figure 8. $A-C$, Effect of repeated intrathecal injection of an inhibitor of PDGF receptor-mediated PTK, AG17, on thermal hyperalgesia $(\boldsymbol{A})$ and tactile allodynia $(\boldsymbol{B}, \boldsymbol{C})$ in sham-operated or nerve-ligated mice. sec, Seconds. $\boldsymbol{B}, \boldsymbol{C}$, Tactile stimulus was applied using filaments with two different bending forces $[0.02 \mathrm{~g}(\boldsymbol{B})$ and $0.16 \mathrm{~g}(\boldsymbol{C})]$. Groups of mice were repeatedly treated intrathecally with AG17 ( $30 \mathrm{nmol} /$ mouse) or vehicle 30 min before surgery (day 0 ) and once per day for 8 consecutive days after surgery. Each point represents the mean \pm SEM of five to seven mice. ${ }^{* *} p<0.01$ and ${ }^{* * *} p<0.001$ versus Vehicle-Sham group; $\# \#<0.01$ and ${ }^{\# \# \#} p<0.001$ versus Vehicle-Ligation group. Error bars represent SEM.
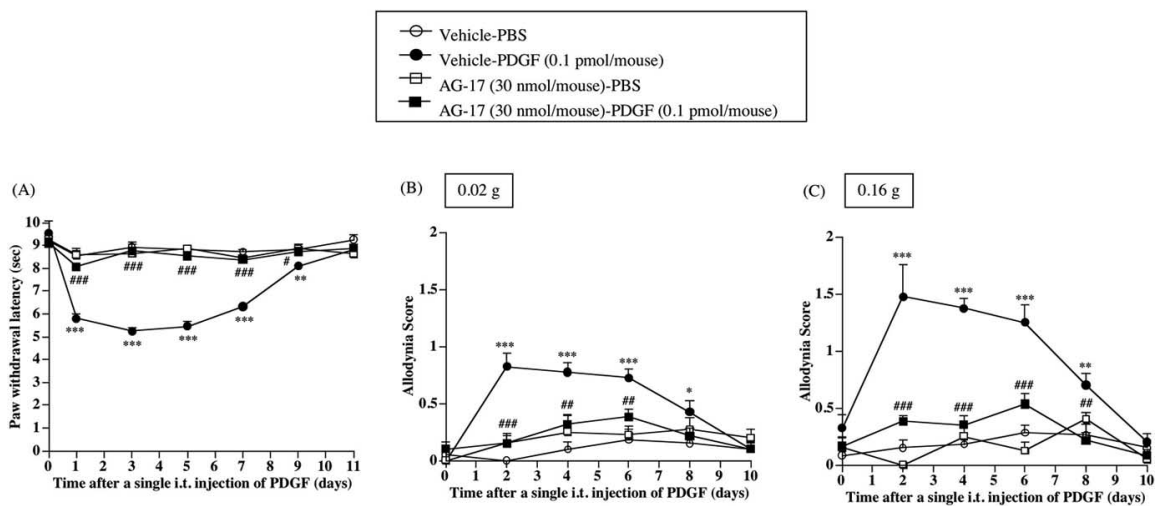

Figure 9. $\boldsymbol{A}-\boldsymbol{C}$, Effect of a single intrathecal injection of PDGF on paw withdrawal responses to the thermal $(\boldsymbol{A})$ and tactile ( $\boldsymbol{B}$, C) stimulus in normal mice. sec, Seconds. $\boldsymbol{B}, \boldsymbol{C}$, Tactile stimulus was performed using filament with two different bending forces $[0.02 \mathrm{~g}(\boldsymbol{B})$ and $0.16 \mathrm{~g}(\boldsymbol{C})]$. Groups of mice were repeatedly treated intrathecally with an inhibitor of PDGF receptor-mediated PTK, AG17 (30 nmol/mouse), or vehicle 30 min before a single intrathecal injection of PDGF and once per day for 11 consecutive days after injection. i.t., Intrathecal. Each point represents the mean \pm SEM of six mice. ${ }^{*} p<0.05{ }^{* *} p<0.01$, and ${ }^{* * *} p<0.001$ versus Vehicle-PBS group; ${ }^{\#} p<0.05,{ }^{\# \#} p<0.01$, and ${ }^{\# \#} p<0.001$ versus Vehicle-PDGF group. Error bars represent SEM. 

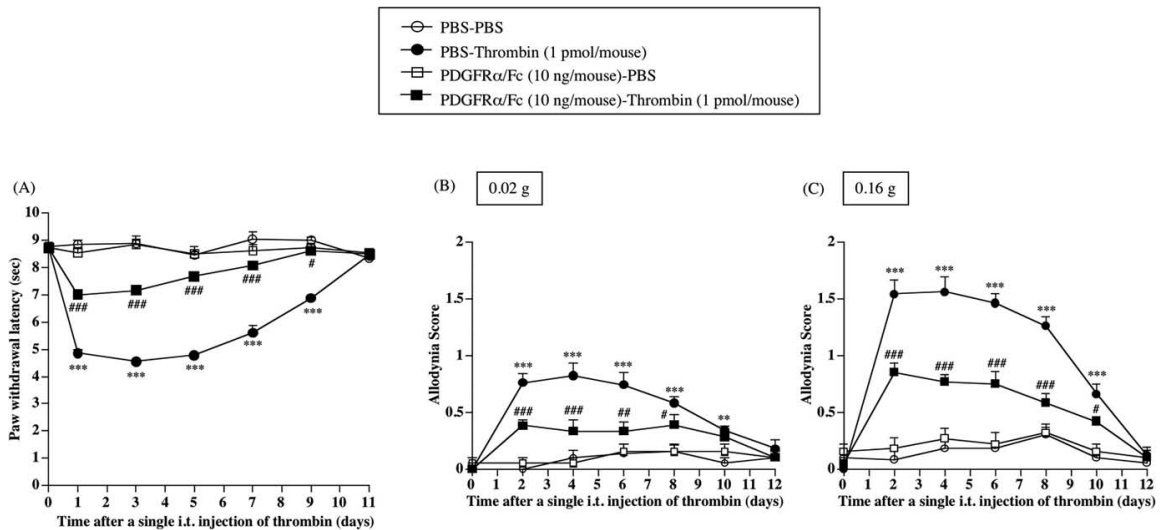

Figure 10. Effect of repeated intrathecal injection of PDGFR $\alpha / F c$ on thermal hyperalgesia or tactile allodynia induced by a single intrathecal injection of thrombin in normal mice. Groups of mice were repeatedly treated intrathecally with PDGFR $\alpha / F c$ (10 $\mathrm{ng} /$ mouse) or sterile PBS $1 \mathrm{~h}$ before the single intrathecal injection of thrombin (1 pmol/mouse) and once per day for 12 consecutive days after injection. Each point indicates the mean \pm SEM of six mice. sec, Seconds; i.t., intrathecal. ${ }^{* *} p<0.01$ and ${ }^{* * *} p<$ 0.001 versus PBS-PBS group; ${ }^{\#} p<0.05,{ }^{\# \#} p<0.01$, and ${ }^{\# \# \#} p<0.001$ versus PBS-Thrombin group. Error bars represent SEM.

(A)

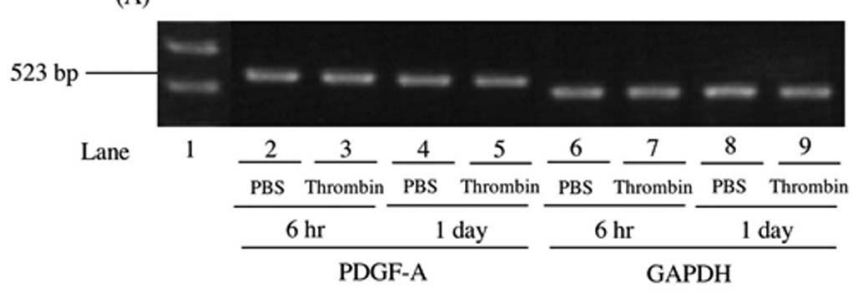

(B)

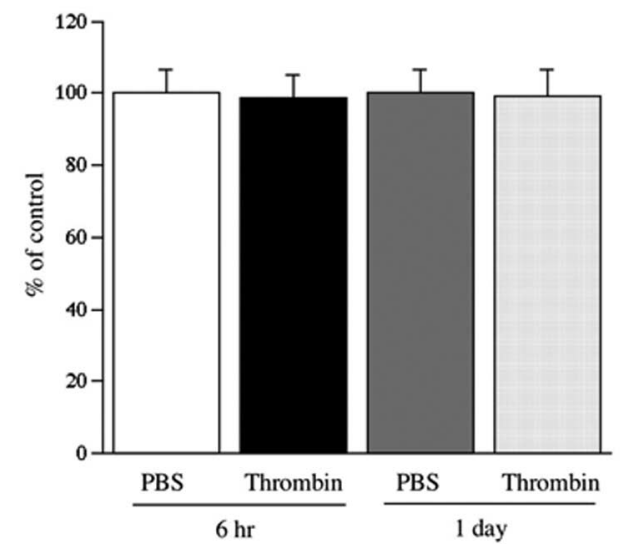

Figure 11. A, Representative reverse transcription-PCR for PDGF-A (lanes 2-5) and an internal standard glyceraldehyde-3-phosphate dehydrogenase (GAPDH; lanes 6-9) mRNAs in the spinal cord at $6 \mathrm{~h}$ and $1 \mathrm{~d}$ after a single intrathecal injection of PBS (lanes 2, 4, 6, and 8) or thrombin (1 pmol/mouse; lanes 3, 5, 7, and 9) in mice. Lane 1 is the indicated marker. $\boldsymbol{B}$, The intensity of the bands was determined in a semiquantitative manner using NIH Image software. Each value for PDGF-A mRNA in thrombin-injected mice was normalized by the value for the respective GAPDH mRNA. The values in thrombin-injected mice are expressed as a percentage of the increase in PBS-injected mice. Each column represents the mean \pm SEM of 10 samples. Error bars represent SEM.

tion in the spinal cord of nerve-ligated mice were evaluated by monitoring the binding of $\left[{ }^{35} \mathrm{~S}\right] \mathrm{GTP} \gamma \mathrm{S}$ to membranes of the mouse spinal cord. In membranes of the L5 lumbar spinal cord from nerve-ligated mice, the concentration-dependence curve for the increased $\left[{ }^{35} \mathrm{~S}\right] \mathrm{GTP} \gamma \mathrm{S}$ binding induced by thrombin was significantly greater than that obtained in sham-operated mice. Furthermore, an immunohistochemical study showed that sciatic nerve ligation produced a clear increase in PAR-1-like IR on lamina II and III of the ipsilateral side of the L5 lumbar spinal dorsal horn compared with that observed in sham-operated mice. The subpopulations of PAR-1-like IR in the spinal cord were colabeled with PKC $\gamma$-like IR, which is highly limited to neuronal cells in the inner part of lamina II of the dorsal horn of the spinal cord, indicating that PAR-1 in the dorsal horn of the L5 lumbar spinal cord may be mostly located in neurons. These findings provide additional evidence that a thrombin/ PAR-1 pathway within neuronal cells of the L5 lumbar spinal cord plays a critical role in the development of a neuropathic pain-like state.

PDGF was first identified in a search for serum factors that stimulate the proliferation of arterial smooth muscle cells (Hoch and Soriano, 2003). Although the $\alpha$-granule of platelets is a major storage site for PDGF, recent studies have shown that PDGF can be synthesized by several different cell types (Heldin and Westermark, 1999). In the present study, PDGF-A-like IR was detected in the superficial laminas and inner part of the L5 lumbar spinal cord in mice. Furthermore, PDGF-A-like IR in the spinal cord was predominantly located on neuronal cells and occasionally located on astrocytes. Under these conditions, we found here for the first time that thermal hyperalgesia and tactile allodynia induced by sciatic nerve ligation were significantly suppressed by repeated intrathecal treatment with PDGFR $\alpha / \mathrm{Fc}$, which can trap an endogenous PDGF, resulting in the prevention of receptor activation. Furthermore, a single intrathecal injection of PDGF produced marked thermal hyperalgesia and tactile allodynia in normal mice after injection, and these effects lasted for 8-9 d after injection. These responses were abolished by intrathecal pretreatment with a potent inhibitor of PTK activity linked to PDGF receptors, AG17. Thermal hyperalgesia and tactile allodynin observed on the ipsilateral side in nerveligated mice was abolished by repeated intrathecal injection of AG17. Considering these findings, the present data suggest that the release of PDGF within the spinal cord by nerve ligation may lead to the development of a neuropathic pain-like state in mice.

Recently, thrombin has been shown to activate platelets and promote the expression or the release of PDGF from platelets. It has also been suggested that the activation of thrombin receptor leads to several intracellular signaling events as well as to the stimulation of endogenous PDGF-A production (Fager, 1995). In the present study, we demonstrated here that PDGF-A-like IR was detected in the neuronal cells and astrocytes within the L5 lumbar spinal cord. It is of interest to note that PDGF-A-like IR was colocalized with PAR-1 in the dorsal horn of the L5 lumbar spinal cord. Together, these findings raise the fascinating possibility that the activation of PAR-1 by thrombin may facilitate the expression or the release of PDGF in neuronal cells and astrocytes located in the spinal cord.

The subsequent study was then undertaken to investigate whether spinal PDGF could be involved in thermal hyperalge- 
sia or tactile allodynia mediated through the thrombin/PAR-1 pathway. The thermal hyperalgesia and tactile allodynia induced by a single intrathecal injection of thrombin were significantly eliminated by repeated intrathecal pretreatment with PDGFR $\alpha / F c$ just before injection and once per day for 12 consecutive days after injection. Under these conditions, there were no differences between PBS- and thrombin-injected mice with regard to mRNA levels of PDGF-A in the spinal cord. These results suggest that thrombin may activate PDGF-Acontaining fibers in the spinal cord without changing the expression of PDGF-A mRNAs, resulting in the induction of hyperalgesia and allodynia.

In a subsequent study, we investigated the colocalization of PAR-1-containing cells with PDGF-A in the dorsal horn of the spinal cord of nerve-ligated mice. Interestingly, almost all of the PAR-1-like IR-positive cells in the dorsal horn of the spinal cord of nerve-ligated mice were clearly colabeled with PDGF-A-like IR, indicating that PDGF-A is mostly located on PAR-1-containing neuronal cells.

Released PDGF acts on PDGF receptor. It is well recognized that the activation of PDGF receptor and its autophosphorylation serve as docking sites for adapter proteins and enzymes such as phosphoinositide-3 kinase, phospholipase C $\gamma$ (PLC $\gamma$ ), and the Src family of tyrosine kinases (Heldin and Westermark, 1999). In particular, the activation of PLC $\gamma$ triggers the facilitation of PKC, which involves in the development of a neuropathic pain-like state (Ohsawa et al., 2000; Zou et al., 2004), through the production of diacylglycerol and inositol 1,4,5triphosphate. Furthermore, brain-derived neurotrophic factor, which was observed almost entirely on presynaptic neurons of the L5 lumbar mouse spinal cord, is an important modulator of the expression of neurotrophin associated with the activation of PKC (Mannion et al., 1999; Yajima et al., 2005). However, we found here that PDGF-A-positive cells are predominantly located on postsynaptic neurons and are widely expressed in the outer and inner parts of the laminas of the spinal cord in mice. These findings suggest that spinal PDGF may be more essential for the development of the neuropathic pain-like state induced by nerve ligation in mice. Although we clearly show here that both PAR-1 and PDGF are responsible for this type of the neuropathic pain-like state, we cannot completely exclude the possibility that these two components are just necessary for the present model to be developed. Thus, additional investigation is needed to identify the role of PAR-1 and PDGF in other types of chronic pain models.

In conclusion, the present data provide novel evidence that thrombin/PAR-1 and PDGF-A-mediated signaling pathway within the spinal cord are directly involved in the development of the neuropathic pain-like state induced by sciatic nerve ligation in mice. Such findings raise the fascinating possibility
(B)

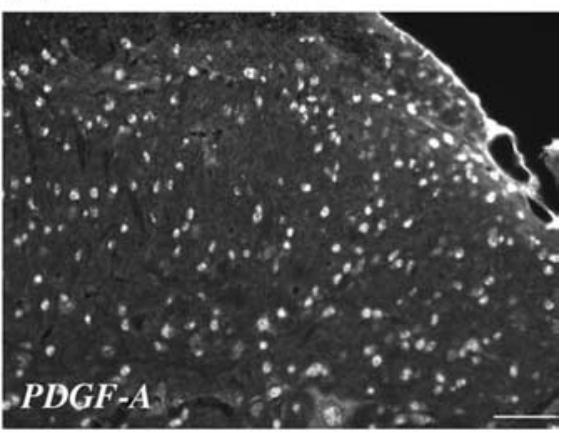

that the activation of upregulated PAR-1 located on the spinal dorsal horn neurons activated by thrombin released after nerve injury may release PDGF in the spinal cord and in turn activate $\operatorname{PDGFR} \alpha$, leading to a neuropathic pain-like state.

\section{References}

Claesson WL (1994) Platelet-derived growth factor receptor signals. J Biol Chem 269:32023-32026.

Dai Y, Moriyama T, Higashi T, Togashi K, Kobayashi K, Yamanaka H, Tominaga M, Noguchi K (2004) Proteinase-activated receptor 2 -mediated potentiation of transient receptor potential vanilloid subfamily 1 activity reveals a mechanism for proteinase-induced inflammatory pain. J Neurosci 24:4293-4299.

Eccleston PA, Funa K, Heldin CH (1993) Expression of platelet-derived growth factor (PDGF) and PDGF alpha- and beta-receptors in the peripheral nervous system: an analysis of sciatic nerve and dorsal root ganglia. Dev Biol 155:459-470.

Fager G (1995) Thrombin and proliferation of vascular smooth muscle cells. Circ Res 77:645-650.

Fang M, Kovacs KJ, Fisher LL, Larson AA (2003) Thrombin inhibits NMDA-mediated nociceptive activity in the mouse: possible mediation by endothelin. J Physiol (Lond) 549:903-917.

Gill JS, Pitts K, Rusnak FM, Owen WG, Windebank AJ (1998) Thrombin induced inhibition of neurite outgrowth from dorsal root ganglion neurons. Brain Res 797:321-327.

Heldin CH, Westermark B (1999) Mechanism of action and in vivo role of platelet-derived growth factor. Physiol Rev 79:1283-1316.

Hoch RV, Soriano P (2003) Roles of PDGF in animal development. Development 130:4769-4784.

Hylden JLK, Wilcox GL (1980) Intrathecal morphine in mice: a new technique. Eur J Pharmacol 67:313-316.

Macfarlane SR, Seatter MJ, Kanke T, Hunter GD, Plevin R (2001) Proteinase-activated receptors. Pharmacol Rev 53:245-282. 
Malmberg A, Chen C, Tonegawa S, Basbaum AI (1997) Preserved acute pain and reduced neuropathic pain in mice lacking PKC $\gamma$. Science 278:279-283.

Mannion RJ, Costigan M, Decosterd I, Amaya F, Ma QP, Holstege JC, Ji RR, Acheson A, Lindsay RM, Wilkinson GA, Woolf CJ (1999) Neurotrophins: peripherally and centrally acting modulators of tactile stimulusinduced inflammatory pain hypersensitivity. Proc Natl Acad Sci USA 96:9385-9390.

Markwardt F (1957) Isolation and chemical characterization of hirudin. Hoppe Seylers Z Physiol Chem 308:147-156.

Markwardt F (2002) Historical perspective of the development of thrombin inhibitors. Pathophysiol Haemost Thromb 32:15-22.

Ohsawa M, Narita M, Mizoguchi H, Suzuki T, Tseng LF (2000) Involvement of spinal protein kinase $\mathrm{C}$ in thermal hyperalgesia evoked by partial sciatic nerve ligation, but not by inflammation in the mouse. Eur J Pharmacol 403:81-85.

Steinhoff M, Vergnolle N, Young SH, Tognetto M, Amadesi S, Ennes HS, Trevisani M, Hollenberg MD, Wallace JL, Caughey GH, Mitchell SE,
Williams LM, Geppetti P, Mayer EA, Bunnett NW (2000) Agonists of proteinase-activated receptor 2 induce inflammation by a neurogenic mechanism. Nat Med 6:151-158.

Suo Z, Citron BA, Festoff BW (2004) Thrombin: a potential proinflammatory mediator in neurotrauma and neurodegenerative disorders. Curr Drug Targets Inflamm Allergy 3:105-114.

Yajima Y, Narita M, Usui A, Kaneko C, Miyatake M, Narita M, Yamaguchi T, Tamaki H, Wachi H, Seyama Y, Suzuki T (2005) Direct evidence for the involvement of brain-derived growth factor in the development of neuropathic pain-like state in mice. J Neurochem 93:584-594.

Zhu WJ, Yamanaka H, Obata K, Dai Y, Kobayashi K, Kozai T, Tokunaga A, Noguchi K (2005) Expression of mRNA for four subtypes of the proteinase-activated receptor in rat dorsal root ganglia. Brain Res 1041:205-211.

Zou X, Lin Q, Willis WD (2004) Effect of protein kinase C blockade on phosphorylation of NR1 in dorsal horn and spinothalamic tract cells caused by intradermal capsaicin injection in rats. Brain Res 1020:95-105. 